\title{
PRODUÇÃO DE MICROPARTÍCULAS DE ALGINATO CONTENDO Flavobacterium columnare INATIVADA PELO MÉTODO DE EMULSÃO PARA VACINAÇÃO DE PEIXES POR VIA ORAL
}

\author{
Priscila Soares Costa Sacchetin e Ângela Maria Moraes* \\ Departamento de Processos Biotecnológicos, Faculdade de Engenharia Química, Universidade Estadual de Campinas, Cidade \\ Universitária “Zeferino Vaz", CP 6066, 13083-970 Campinas - SP, Brasil \\ Carlos Augusto Gomes Leal e Henrique César Pereira Figueiredo \\ Departamento de Medicina Veterinária, Universidade Federal de Lavras, Campus Universitário, CP 37, 37200-000 Lavras - MG, Brasil
}

Recebido em 6/1/09; aceito em 7/8/09; publicado na web em 21/1/10

\begin{abstract}
PRODUCTION BY EMULSION METHOD OF ALGINATE MICROPARTICLES CONTAINING INACTIVATED Flavobacterium columnare FOR ORAL FISH VACCINATION. Alginate microparticles were prepared by an emulsion method aiming oral controlled release of antigens to fish. The effects of emulsification temperature and impeller type on particle morphology, average diameter, and size distribution were evaluated. Microparticles contaning formalin-killed Flavobacterium columnare cells (a model antigen) were prepared and characterized regarding bacterial release and particle stability when exposed to Nile tilapia (Oreochromis niloticus) typical gastrointestinal conditions. This methodology allowed the production of microparticles containing up to $14.3 \mathrm{~g} / \mathrm{L}$ of bacterin, stable at a $\mathrm{pH}$ range from 2.0 to 9.0 for $12 \mathrm{~h}$ and smaller than $35 \mu \mathrm{m}$.
\end{abstract}

Keywords: alginate microparticles; emulsion; fish vaccine.

\section{INTRODUÇÃO}

Dentre as atividades que têm demonstrado grande potencial quanto ao acesso e fornecimento de alimentos ricos em proteínas, destaca-se a piscicultura. Nesses sistemas, as altas densidades de estocagem, o manejo intenso dos animais e a baixa qualidade da água contribuem para a ocorrência de doenças infecciosas, um dos principais entraves para o sucesso desta atividade no país. Com a intensificação e ampliação da piscicultura, a ocorrência destas doenças tende a aumentar significativamente.

Dentre as enfermidades diagnosticadas em peixes, as de etiologia bacteriana estão entre as mais impactantes, devido às altas taxas mortalidade e ao custo elevado para sua prevenção e controle. Destaca-se, neste sentido, a espécie Flavobacterium columnare, que é considerada um patógeno de ocorrência mundial capaz de causar doenças em praticamente todos os tipos de peixes de água doce. ${ }^{1,2}$ Atualmente, o tratamento da doença é realizado através de banhos com substâncias desinfetantes e antibioticoterapia oral. ${ }^{3}$ No entanto, o uso de antibióticos em sistemas de cultivo de peixes é bastante problemático, uma vez que o uso repetitivo destes pode levar ao desenvolvimento de microorganismos resistentes no ambiente e na microbiota dos animais. ${ }^{4}$

Uma alternativa mais conveniente é a imunoprofilaxia, que consiste no estímulo da imunidade específica e não específica do peixe pelo contato com patógenos atenuados e/ou inativados. Sua administração na forma de vacinas leva a uma diminuição da dependência do uso de antibióticos. ${ }^{5}$ Dentre os métodos de imunização que se têm mostrado atraentes, destacam-se as formulações injetáveis e as administradas por imersão e via oral. A vacinação oral, na qual se mistura o agente vacinal à ração, é uma técnica pouco invasiva, de fácil administração, de custo moderado frente aos demais métodos e que provoca estresse mínimo nos peixes sendo, por estas razões, bastante vantajosa.

Assim, pesquisas focadas na proteção dos antígenos contra os processos digestivos e de sua possível decomposição durante a passagem pelo trato gastrointestinal têm sido realizadas, ${ }^{5}$ sendo uma estratégia comum de proteção a encapsulação do agente vacinal em

*e-mail: ammoraes@feq.unicamp.br micropartículas. Estes sistemas carreadores microparticulados orais não só necessitam se associar a uma alta quantidade de antígeno, bem como precisam superar problemas relacionados à fraca permeabilidade através da mucosa gastrointestinal e à transposição da barreira de absorção durante a primeira fase de metabolização, de modo que os imunógenos cheguem à corrente sanguínea da forma mais preservada possível, ${ }^{6}$ para que tenham maiores chances de atuarem de forma eficiente como agentes de imunização.

Em mamíferos, as micropartículas devem possibilitar o reconhecimento e o transporte dos antígenos nelas incorporados pelas células M e pelas placas de Peyer. Neste sentido, as micropartículas idealmente não devem exceder $10 \mu \mathrm{m}$ em tamanho. ${ }^{7-9}$ Entretanto, peixes não possuem placas de Peyer e células M. ${ }^{10}$ Nestes animais, supostamente, o principal processo de absorção de antígenos através das células epiteliais da mucosa intestinal (enterócitos) é a pinocitose,${ }^{11}$ de forma que partículas de diferentes tamanhos poderiam ser empregadas com distintas funções. Se apenas a proteção do agente antigênico do trato gastrintestinal é requerida, partículas com diâmetros até $300 \mu \mathrm{m}$ podem ser usadas com sucesso, no entanto, uma faixa de diâmetros mais estreita, entre 5 e $50 \mu \mathrm{m}$, seria a mais indicada. ${ }^{12}$ Nesta faixa de tamanho, Romalde e colaboradores ${ }^{13}$ observaram níveis eficientes de proteção de trutas contra Lactococcus garvieae utilizando micropartículas de alginato de cerca de $30 \mu \mathrm{m}$, enquanto Tian e colaboradores ${ }^{9}$ obtiveram efetiva indução de resposta imune em linguados empregando micropartículas de quitosana com diâmetro da ordem de $10 \mu \mathrm{m}$. Para tilápias, não foram localizados relatos do uso de micropartículas como sistema de liberação controlada de agentes vacinais, supondo-se, no entanto, que a faixa de tamanhos de 5 a $50 \mu \mathrm{m}$ seria apropriada.

Dentre os polímeros frequentemente utilizados para a incorporação de agentes vacinais destaca-se o alginato, amplamente utilizado tanto na indústria farmacêutica quanto alimentícia, e que possui características como biocompatibilidade, bioadesividade, condições brandas de gelificação e sensibilidade a distintas condições de $\mathrm{pH} .{ }^{14} \mathrm{O}$ método de gelificação interna via emulsão proposto por Poncelet e colaboradores ${ }^{15}$ é bastante utilizado para a preparação de micropartículas de alginato 
e, dependendo do objetivo, podem-se modificar as características das micropartículas pela alteração dos parâmetros operacionais empregados durante sua produção. ${ }^{16}$ Dentre as variáveis que afetam a formação de micropartículas produzidas por emulsão podem ser incluídas a concentração de alginato, a concentração do agente antigênico, a composição do agente gelificante, ${ }^{12,17-21} \mathrm{o}$ tipo de equipamento usado na formação da emulsão, a taxa de agitação empregada, ${ }^{19}$ a temperatura, o tipo e a concentração de emulsificante ${ }^{22}$ e a proporção entre as fases aquosa e não-aquosa. O tamanho das micropartículas está diretamente associado com a concentração e a viscosidade da solução de alginato empregada, observando-se que baixas concentrações favorecem a redução do tamanho das partículas. ${ }^{12,18,23}$ Entretanto, concentrações reduzidas diminuem também a resistência mecânica e a estabilidade das micropartículas em condições gastrointestinais. ${ }^{17} \mathrm{O}$ aumento na proporção de 10 para $50 \%$ da fase aquosa aumenta o diâmetro das micropartículas, sendo que partículas menores são obtidas quando esta proporção é fixada em $10 \% .{ }^{23} \mathrm{O}$ uso de emulsificantes como o Span 80 também reduz o tamanho das micropartículas, pela diminuição da tensão superficial das gotas, prevenindo sua coalescência. ${ }^{18}$ Micropartículas produzidas na presença de altas concentrações de emulsificantes tendem a ser moderadamente deformadas quando comparadas às preparadas empregando-se quantidades menores de surfatantes. ${ }^{23}$

Desta forma, o propósito deste trabalho foi estudar a preparação das micropartículas de alginato capazes de encapsular células inativadas de Flavobacterium columnare, desenvolvidas para a vacinação oral de tilápia do Nilo (Oreochromis niloticus), importante espécie na aquicultura mundial e nacional. Foram avaliados os efeitos da variação da temperatura e o uso de diferentes impelidores no diâmetro de micropartículas produzidas com base no protocolo proposto por Rodrigues e colaboradores ${ }^{23}$ avaliando-se também o comportamento in vitro destes sistemas microestruturados, sua estabilidade e perfil de liberação do agente antigênico.

\section{PARTE EXPERIMENTAL}

\section{Material}

Alginato de baixa viscosidade (Sigma-Aldrich Co., EUA), Span 80 (Fluka ChemiKa, Suíça), cloreto de cálcio di-hidratado (Merck, Brasil) e óleo de milho Liza (Cargill do Brasil) foram usados para a preparação das micropartículas. A bactéria Flavobacterium columnare BZ-1, previamente isolada e caracterizada, ${ }^{24}$ foi cultivada e inativada no Laboratório de Doenças de Animais Aquáticos, UFLA/MG, Brasil. Todos os demais reagentes utilizados possuíam grau analítico.

\section{Métodos}

\section{Obtenção do agente antigênico}

As células foram cultivadas em meio Agar Hsu-Shotts (MSH) por $24 \mathrm{~h}$ à $26^{\circ} \mathrm{C}$. Posteriormente, uma colônia foi selecionada e então inoculada em $200 \mathrm{~mL}$ de caldo MSH e cultivada por $24 \mathrm{~h}$ a 25 ${ }^{\circ} \mathrm{C}$, sendo agitada continuamente a $150 \mathrm{rpm}$. Em seguida, as células foras centrifugadas a $3.500 \mathrm{rpm}$ por $30 \mathrm{~min}$ e o pellet bacteriano foi lavado por duas vezes com tampão fosfato salina (PBS) a $1 \mathrm{~mol}$ $\mathrm{L}^{-1}$, em $\mathrm{pH} 7,0$. As bactérias foram inativadas pela ressuspensão dos pellets no mesmo volume inicial de $\mathrm{PBS}$ a $1 \mathrm{~mol} \mathrm{~L}^{-1}$ contendo $0,2 \%$ de formaldeído, sendo posteriormente armazenadas a $4{ }^{\circ} \mathrm{C}$ por 24 h. O inóculo, então, foi centrifugado $\left(6.000 \mathrm{x} \mathrm{g}\right.$, a $4{ }^{\circ} \mathrm{C}$ por $\left.20 \mathrm{~min}\right)$ e o pellet lavado por duas vezes com solução salina $(\mathrm{NaCl}$ a $0,9 \%$ $\mathrm{m} / \mathrm{v}$ ) estéril. Antes da incorporação nas micropartículas de alginato, as células foram centrifugadas a $10.000 \mathrm{rpm}$ (centrífuga modelo 5804R, Eppendorf) por $10 \mathrm{~min}$ a $6{ }^{\circ} \mathrm{C}$, sendo lavadas três vezes e ressuspendidas em solução salina a pH 7,4.

\section{Preparação das micropartículas}

A produção das micropartículas foi baseada no método proposto por Rodrigues e colaboradores. ${ }^{23}$ Alíquotas de $7 \mathrm{~mL}$ de solução aquosa de alginato de sódio a 3,5\% (m/v) foram emulsificadas a $2.000 \mathrm{rpm}$ por 5 min em 63 mL de óleo de milho contendo 0,2\% (v/v) de Span 80. Quando requerido, incorporou-se à solução de alginato alíquotas da suspensão do agente antigênico em concentrações ajustadas na faixa de 0,57 a $14,6 \mathrm{~g} \mathrm{~L}^{-1}$, em termos de massa seca celular por mililitro de solução de alginato. À emulsão formada, adicionaram-se $70 \mathrm{~mL}$ de solução gelificante composta por $5,98 \mathrm{~g} \mathrm{de} \mathrm{CaCl}_{2} \cdot 2 \mathrm{H}_{2} \mathrm{O}$ dissolvidos em 33,87 mL de água deionizada, 33,87 mL de etanol e 2,26 mL de ácido acético glacial, sob agitação de $2.000 \mathrm{rpm}$ por $10 \mathrm{~min}$. Depois que as micropartículas foram formadas, realizou-se o processo de recuperação das mesmas por inversão da emulsão, vertendo-se esta em $150 \mathrm{~mL}$ de solução de cloreto de cálcio a $0,05 \mathrm{~mol} \mathrm{~L}^{-1}$. Após a separação da fase oleosa da fase aquosa, as micropartículas foram filtradas em papel de filtro (poros de $14 \mu \mathrm{m}$ de diâmetro). Em seguida, as micropartículas foram coletadas e armazenadas em frascos contendo água deionizada e armazenadas à temperatura de $4{ }^{\circ} \mathrm{C}$. Todas as amostras foram preparadas, no mínimo, em duplicata.

O efeito da variação de temperatura sobre as características das micropartículas formadas foi avaliado variando-se a temperatura no vaso de mistura de 20 a $35{ }^{\circ} \mathrm{C}$. Para o estudo do efeito do uso de diferentes impelidores na formação das micropartículas, visando a obtenção de emulsões com diferentes tamanhos de gotículas dispersas, foram utilizados impelidores dos tipos naval, pás inclinadas, âncora perfurada e centrífuga, mostrados nas Figuras $1 \mathrm{~S}, 2 \mathrm{~S}, 3 \mathrm{~S}$ e $4 \mathrm{~S}$ do material suplementar.

Todos os experimentos foram realizados utilizando-se agitador mecânico modelo Q250M (Quimis), vaso de agitação de fundo arredondado encamisado de aço inoxidável com dimensões internas de $8 \mathrm{~cm}$ de diâmetro por $15 \mathrm{~cm}$ de altura e banho termostático com circulação de fluido modelo Q214M (Quimis).

As análises de variância (ANOVA) foram realizadas através do software Origin, versão 5.0 (OriginLab). Níveis de significância $p$ menores que 0,05 para os diâmetros médios das micropartículas foram considerados como estatisticamente significativos neste estudo.

\section{Análise da viscosidade da emulsão}

A viscosidade da emulsão formada pela mistura da solução de alginato em óleo de milho foi avaliada em reômetro Haake RheoStress 1 (Thermo Electron Corporation), em cuba de geometria Z20 Din Titanium com um volume de amostra de 8,2 mL. O sistema era acoplado a um banho termostático (Haake DC 30) e empregouse uma rampa de temperatura com taxa de elevação de $1{ }^{\circ} \mathrm{C} / \mathrm{min}$, mantendo-se tensão constante de $10 \mathrm{~Pa}$.

\section{Análise morfológica}

A morfologia e as características superficiais das micropartículas foram avaliadas através do uso de microscópio óptico modelo Q500IW (Leica).

\section{Análise de diâmetro médio e distribuição de tamanho das micropartículas}

O diâmetro médio e a distribuição de tamanhos das micropartículas foram avaliados através de espectrofotometria de espalhamento a laser (Mastersizer S, modelo S-MAM 5005, Malvern Instruments). Cada medida foi efetuada cinco vezes para amostras de, no mínimo, três lotes diferentes, compreendendo até $15 \%$ da massa de cada lote por amostra.

\section{Determinação da eficiência de incorporação da Flavobacterium columnare}

A eficiência de incorporação da massa bacteriana foi avaliada pela razão entre a massa de agente efetivamente encapsulado e a 
quantidade inicial empregada na formação das micropartículas, ambas determinadas por espectrofotometria de luz visível com base na análise gravimétrica da massa seca de um volume conhecido de suspensão celular. Basicamente, suspendeu-se $1 \mathrm{~g}$ de micropartículas úmidas em $9 \mathrm{~mL}$ de citrato de sódio a $0,05 \mathrm{~mol} \mathrm{~L}^{-1}$, de modo a obter-se a liberação das células bacterianas incorporadas pela dissolução da matriz de alginato. A amostra foi mantida nesta solução, sob agitação magnética, a $26{ }^{\circ} \mathrm{C}$ por $12 \mathrm{~h}$, sendo posteriormente centrifugada a $10.000 \mathrm{rpm}$ por $15 \mathrm{~min}$. O sobrenadante foi descartado e o sedimento (composto pelas células) foi ressuspendido em $1 \mathrm{~mL}$ de solução salina a $0,9 \%(\mathrm{~m} / \mathrm{v})$. A concentração bacteriana foi determinada por análise em espectrofotômetro modelo DU640 (Beckman) a 600 nm, de forma comparativa a curvas de calibração obtidas com diferentes lotes de suspensão de bactérias tratados de acordo com o mesmo procedimento e cujas concentrações celulares foram determinados pelo método da análise da massa seca, filtrando-se um volume conhecido de suspensão celular através de uma membrana com poros de $0,22 \mu \mathrm{m}$ e secando-se a membrana a $35^{\circ} \mathrm{C}$ até a obtenção de massa constante. $\mathrm{O}$ efeito dos componentes do gel foi descontado, tendo-se por base o tratamento similar de uma amostra com a mesma massa de micropartículas não contendo células.

Avaliação da liberação das células incorporadas e da estabilidade in vitro das micropartículas

A estabilidade das micropartículas bem como a liberação das bactérias incorporadas em soluções que simulavam as condições gastrointestinais foram avaliadas pela incubação das micropartículas úmidas em soluções com diferentes valores de $\mathrm{pH}$. Amostras contendo 0,2 g de micropartículas foram incubadas (banho Dubnoff, modelo TE-053) à $26^{\circ} \mathrm{C}$ por $12 \mathrm{~h}$ (tempo médio de tráfego do alimento no trato gastrointestinal das tilápias do Nilo ${ }^{23} \mathrm{em} 1,8 \mathrm{~mL}$ de água deionizada a pH 2,0 e 4,5 (previamente ajustada com $\mathrm{HCl}$ ), PBS a pH 7,4 e tampão Tris a pH 9,0. Depois de incubadas, as amostras nas diferentes condições foram centrifugadas a $1.000 \mathrm{rpm}$ por $30 \mathrm{~min}$, para a remoção das partículas, mas não das bactérias suspensas, sendo o sobrenadante analisado espectrofotometricamente a $600 \mathrm{~nm}$ de modo a se obter a quantidade de bactérias liberadas, empregando-se, para tal, curvas de calibração obtidas com cada solvente de forma isolada. A estabilidade das micropartículas foi analisada através de microscopia óptica após o tratamento com as diferentes soluções de incubação.

\section{RESULTADOS E DISCUSSÃO}

Diversos fatores e condições operacionais foram investigados de modo a se observar os efeitos dos mesmos sobre a formação da emulsão e, consequentemente, da produção de micropartículas com características morfológicas e tamanhos hipoteticamente adequados para a imunização de peixes por via oral. Os resultados obtidos são discutidos a seguir.

\section{Efeito da temperatura sobre a formação das micropartículas}

As variações observadas no diâmetro médio das micropartículas preparadas em diferentes temperaturas estão indicadas na Tabela 1. Neste ensaio foi empregado um impelidor de pás inclinadas cujo desempenho foi descrito em trabalho prévio, ${ }^{23} \mathrm{o}$ mesmo se aplicando às condições de agitação.

Os diâmetros médios das micropartículas obtidas não foram estatisticamente diferentes $(p<0,05)$. Observou-se que a temperatura que promoveu melhores resultados globais foi a de $25^{\circ} \mathrm{C}$. Nesta condição, como pode ser observado na Figura 1, constatou-se a formação de micropartículas morfologicamente regulares, com adequada distribuição de tamanhos (apresentando curva unimodal, como mostrado
Tabela 1. Diâmetros médios das micropartículas preparadas em distintas temperaturas

\begin{tabular}{cc}
\hline Temperatura $\left({ }^{\circ} \mathrm{C}\right)$ & Diâmetro médio $(\mu \mathrm{m})$ \\
\hline 20 & $40 \pm 3$ \\
25 & $43 \pm 1$ \\
30 & $40 \pm 1$ \\
35 & $44 \pm 2$ \\
\hline
\end{tabular}

na Figura 2) e pouca retenção de óleo. Em experimentos realizados a $20{ }^{\circ} \mathrm{C}$ foi verificada a formação de micropartículas com tamanhos muito variados, desde muito grandes a muito pequenas, o que aumentou a faixa de distribuição de tamanhos. Além disso, foi observado o aparecimento de dois picos secundários na curva na distribuição de tamanhos, que podem ser oriundos da agregação das micropartículas no sistema de análise e da grande retenção de óleo. Para os ensaios que utilizaram as temperaturas de 30 e $35{ }^{\circ} \mathrm{C}$, verificou-se gradual tendência à formação de micropartículas maiores, oriundas da grande coalescência do sistema e a formação de micropartículas muito pequenas, o que compromete a obtenção de picos estreitos de distribuição de tamanhos das micropartículas. Também se observou uma forte tendência à retenção de óleo nestas amostras o que, apesar de dificultar a análise de distribuição de tamanhos das micropartículas, não tem implicações do ponto de vista de aplicação do produto final (a presença de resíduos do óleo não afeta a palatabilidade da ração, visto que óleos vegetais são costumeiramente utilizados para a administração de antibióticos e vitaminas para peixes via ração).

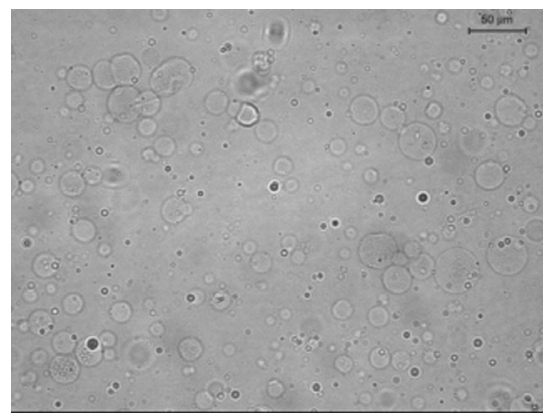

Figura 1. Aspecto morfológico típico em microscópio óptico (aumento de 200x) das micropartículas de alginato produzidas a $25^{\circ} \mathrm{C}$

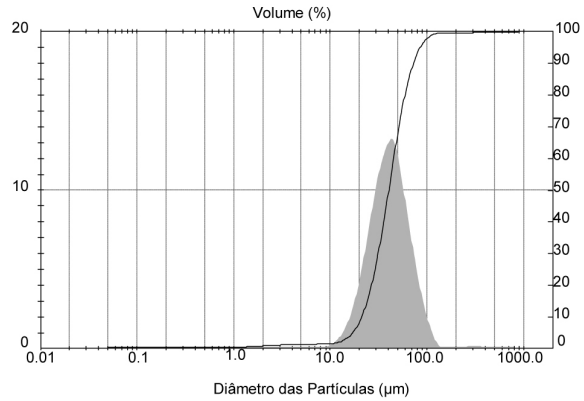

Figura 2. Perfil de distribuição de tamanho das micropartículas de alginato produzidas a $25^{\circ} \mathrm{C}$

Os diferentes comportamentos observados podem ser explicados pela alteração na viscosidade das soluções e, consequentemente, nas propriedades da emulsão. ${ }^{25} \mathrm{~A}$ viscosidade da emulsão tende a diminuir com o aumento da temperatura, variando de $70,4 \mathrm{mPa} . \mathrm{s}$ a $20^{\circ} \mathrm{C}$ para $38,1 \mathrm{mPa}$.s a $35^{\circ} \mathrm{C}$, principalmente devido à diminuição da viscosidade da fase contínua, no caso, o óleo, que neste mesmo intervalo 
de temperatura variou a viscosidade de 69,0 a 37,9 mPa.s. Estudos realizados por Almutairi ${ }^{25}$ demonstraram que o aumento da temperatura de 25 até $80{ }^{\circ} \mathrm{C}$ reduz a viscosidade de emulsões produzidas a diferentes taxas de agitação. $\mathrm{Pal}^{26}$ observou considerável influência da viscosidade de emulsões sobre o tamanho das gotas formadas, apontando uma clara relação entre o aumento da temperatura e a diminuição da viscosidade e, por consequência, a formação de gotículas maiores. Como demonstrado no presente trabalho, o aumento da temperatura de formação da emulsão acarretou na obtenção de partículas maiores, uma vez que a elevação da temperatura tende a desestabilizar a emulsão, afetando as forças interfaciais e aumentando a coalescência das gotas do sistema. Resultados similares foram obtidos por Opawale e Burguess, ${ }^{27}$ que constataram que a elasticidade interfacial de surfatantes como o Span 80 é alterada pela variação de temperatura empregada no sistema. Apesar de menos sensível às alterações de temperatura em comparação a outros surfatantes lipofílicos de cadeia saturada, o Span 80 tende a favorecer a formação de emulsões mais estáveis quando a quantidade de sais na fase aquosa é baixa ou ausente e quando se faz uso de temperaturas mais brandas de formação da emulsão, ${ }^{27}$ como na presente situação. Como vantagem adicional, o uso de temperaturas mais amenas tem menor potencial de causar a degradação dos antígenos.

Desta forma, a coalescência das gotas da fase dispersa pode ser reduzida pelo aumento da viscosidade da fase contínua, de modo a diminuir as colisões entre as gotas, o que poderia levar à formação de micropartículas maiores ou à sua ruptura, resultando na formação de grandes aglomerados. ${ }^{28}$ Apesar de a $20{ }^{\circ} \mathrm{C}$ as micropartículas produzidas apresentarem um diâmetro médio menor ( $40 \mu \mathrm{m} \pm 3)$, esta temperatura forneceu dois picos de distribuição de tamanhos, o que poderia comprometer a encapsulação do agente. Assim, nos ensaios subsequentes utilizou-se a temperatura de $25^{\circ} \mathrm{C}$.

\section{Efeito do tipo de impelidor sobre a formação das micropartículas}

O uso de diferentes tipos de impelidores resultou em micropartículas com diâmetros médios variando conforme indicado na Tabela 2. Neste caso as variações foram estatisticamente diferentes $(p<0,05)$. As micropartículas produzidas com o impelidor do tipo pás inclinadas apresentaram boa esfericidade e adequada distribuição de tamanhos, porém observou-se que o uso deste tipo de hélice propiciou maior retenção de óleo. Nos experimentos realizados com o impelidor de âncora perfurada notou-se a presença de micropartículas muito pequenas, com formação de centros de aglomeração e de micropartículas de formato irregular. Nos ensaios em que foi que utilizado o impelidor tipo centrífugo, ocorreu a formação de populações de micropartículas com tamanhos acima de $50 \mu \mathrm{m}$ e de micropartículas muito pequenas, de cerca de $4 \mu \mathrm{m}$ de diâmetro. Este tipo de comportamento é indesejável, pois propicia uma encapsulação ineficiente do antígeno, resultando em distribuição não uniforme do número de bactérias por micropartículas. Tal comprometimento da uniformidade pode afetar a eficiência de imunização dos peixes.

Com base nos ensaios realizados, constatou-se que o impelidor mais adequado para a formação de micropartículas de alginato é a hélice do tipo naval, que resulta em apenas moderada perda de material por espirramento, menor retenção de óleo, micropartículas com boa distribuição de tamanhos e esfericidade, como se pode observar nas Figuras 3 e 4, que é atualmente o tipo de impelidor mais frequientemente relatado na literatura para a formação de micropartículas de alginato. ${ }^{21,29,30}$

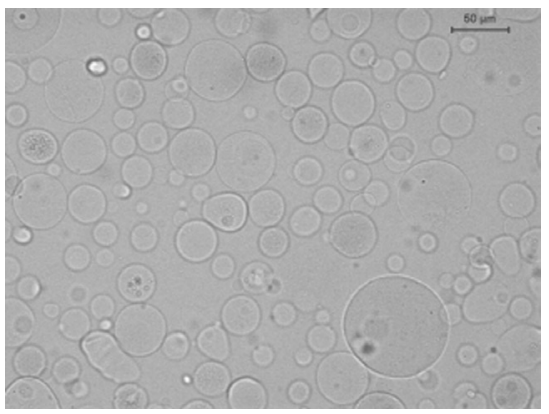

Figura 3. Aspecto morfológico típico em microscópio óptico (aumento de 200x) das micropartículas de alginato produzidas com impelidor naval

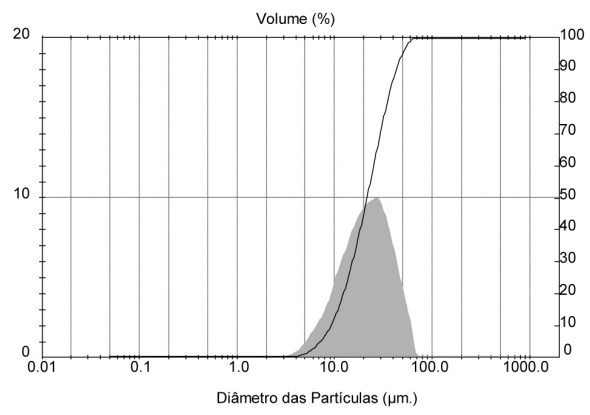

Figura 4. Perfil de distribuição de tamanho das micropartículas de alginato produzidas com impelidor naval

Segundo Kichatov e colaboradores, ${ }^{31}$ o efeito do tipo de impelidor sobre a distribuição de tamanhos das gotas da emulsão formada é de difícil avaliação, devido especialmente às dificuldades associadas quanto à modelagem da coalescência das gotas. Entretanto, supõe-se que os diferentes resultados obtidos muito provavelmente decorrem do tipo de fluxo produzido por cada um dos impelidores testados, fluxos estes abordados em detalhes por Joaquim Jr e colaboradores. ${ }^{32}$ O impelidor do tipo naval apresenta predominantemente componentes de velocidade axial que, para a produção de emulsões do tipo água/

Tabela 2. Características das micropartículas produzidas empregando diferentes impelidores

\begin{tabular}{|c|c|c|c|c|}
\hline Impelidor & Diâmetro médio $(\mu \mathrm{m})$ & $\begin{array}{l}\text { Aspecto morfológico } \\
\text { das micropartículas }\end{array}$ & $\begin{array}{l}\text { Perdas por } \\
\text { espirramento }\end{array}$ & Presença de óleo residual \\
\hline Naval & $26 \pm 2$ & $\begin{array}{c}\text { Variação de tamanhos pequena } \\
\text { Formato esférico }\end{array}$ & Moderada & Pequena \\
\hline Pás inclinadas & $35 \pm 2$ & $\begin{array}{c}\text { Variação de tamanhos pequena } \\
\text { Formato esférico }\end{array}$ & Pequena & Moderada \\
\hline Âncora Perfurada & $21 \pm 1$ & $\begin{array}{l}\text { Variação de tamanhos elevada } \\
\text { Formato irregular }\end{array}$ & Elevada & Moderada \\
\hline Centrífugo & $24 \pm 1$ & $\begin{array}{c}\text { Variação de tamanhos elevada } \\
\text { Formato esférico }\end{array}$ & Elevada & Moderada \\
\hline
\end{tabular}


óleo, é mais conveniente, visto que impelidores que produzem fortes componentes de velocidade do tipo tangencial, como no caso dos demais impelidores, tendem a aumentar as perdas por espirramento de material no vaso de mistura durante a homogeneização. Como verificado anteriormente, as componentes do tipo axial produzem micropartículas com boa distribuição de diâmetros, já as componentes do tipo radial/tangencial (como é o caso do impelidor de pás inclinadas) tendem a formar micropartículas com diâmetros médios maiores.

O uso do impelidor do tipo âncora perfurada resultou em micropartículas deformadas, com grande distribuição de tamanhos, o que é bastante problemático do ponto de vista da aplicação final. A formação de partículas com o uso do impelidor tipo centrífugo também é inadequada, uma vez que produz micropartículas com grande distribuição de tamanhos, apesar de estas terem formato regular e esférico.

Apesar destes impelidores apresentarem componentes de velocidade predominantes, seus padrões de fluxo poderiam ser alterados por parâmetros como o diâmetro e a posição do impelidor, a viscosidade do líquido, a utilização de mais de um impelidor por tanque e o emprego de chicanas.

\section{Incorporação de Flavobacterium columnare}

Micropartículas de alginato foram produzidas na presença de diferentes concentrações da suspensão celular, na temperatura de 25 ${ }^{\circ} \mathrm{C}$, com o uso da hélice naval. Os resultados globais obtidos em termos de eficiência de incorporação do agente vacinal e dos diâmetros médios das micropartículas estão indicados na Tabela 3.

Tabela 3. Características das micropartículas preparadas na presença de diferentes concentrações iniciais de suspensão celular (em termos de massa seca celular por litro de solução de alginato)

\begin{tabular}{ccc}
\hline $\begin{array}{c}\text { Concentração da } \\
\text { suspensão celular }\left(\mathrm{g} \mathrm{L}^{-1}\right)\end{array}$ & $\begin{array}{c}\text { Eficiência de } \\
\text { incorporação }(\%)\end{array}$ & $\begin{array}{c}\text { Diâmetro médio } \\
(\mu \mathrm{m})\end{array}$ \\
\hline 0,57 & 98,7 & $24 \pm 1$ \\
6,48 & 99,3 & $27 \pm 1$ \\
14,6 & 98,2 & $32 \pm 1$ \\
\hline
\end{tabular}

Em todos os casos, as micropartículas produzidas apresentaram formato esférico e regular. A maior diferença nas características morfológicas em relação às amostras livres de bacterina foi o aumento da rugosidade superficial (exemplificado nas Figuras 5 e 6 ), aumento este intensificado à medida que se eleva a concentração celular. As micropartículas apresentaram adequado perfil de distribuição de tamanhos, com pouca variação no diâmetro médio, como se pode observar na Tabela 3. Isso pode ter ocorrido em função da bactéria utilizada apresentar pequeno tamanho $(0,3$ a $0,6 \mu \mathrm{m}$ de diâmetro, variando de 3,5 a 10,5 $\mu \mathrm{m}$ de comprimento) ${ }_{,}^{33}$ o que permite a encapsulação de uma elevada quantidade de bactérias sem que ocorram grandes alterações no diâmetro das micropartículas. Este resultado é condizente com o obtido por Rodrigues e colaboradores, ${ }^{23}$ que observaram que ao se aumentar a concentração da suspensão de células Aeromonas hydrophila na solução de alginato para a formação das micropartículas, também se observava um aumento no diâmetro médio da população. Isto se deve provavelmente à quantidade excessiva de antígeno, que dificulta a formação de gotas de alginato menores e, com isso, aumenta discretamente o diâmetro médio das micropartículas produzidas.

\section{Estabilidade e liberação in vitro}

O trato gastrointestinal dos peixes comumente varia de muito ácido, na região do estômago, devido à intensa produção de pepsinogênio

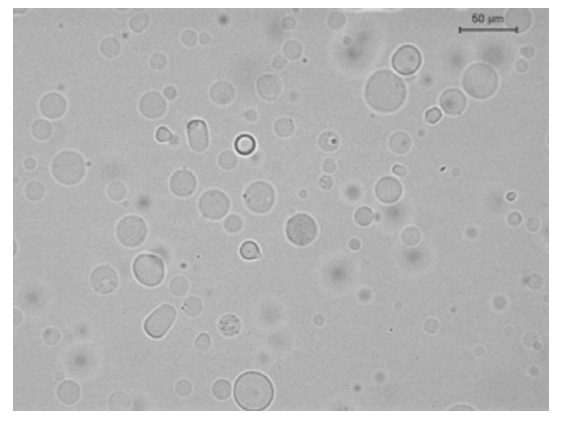

Figura 5. Aspecto morfológico típico das micropartículas obtidas sem o agente antigênico

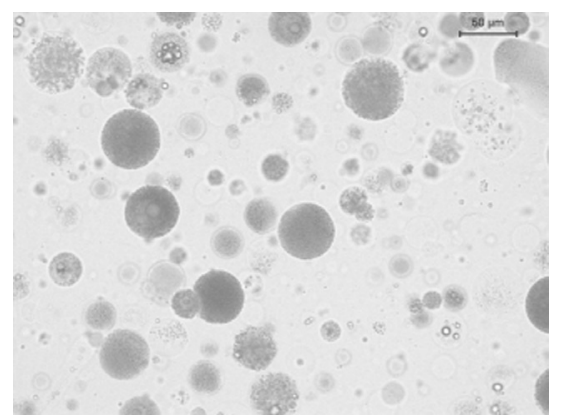

Figura 6. Aspecto morfológico típico das micropartículas contendo 14,3 g $L^{-1}$ de suspensão de Flavobacterium columnare

e ácido clorídrico durante a alimentação, com valores de $\mathrm{pH}$ entre 2,0 e 4,5, até levemente alcalino na região do intestino, que apresenta $\mathrm{pH}$ entre 7,0 a 9,0. ${ }^{23}$ Desta forma, fez-se necessário avaliar a estabilidade das micropartículas nas condições da região gástrica dos peixes, bem como observar qual o perfil de liberação do agente antigênico nestas condições. As amostras contendo $14,3 \mathrm{~g}$ de bactéria/L de gel de alginato foram incubadas por $12 \mathrm{~h}$ em soluções que simulavam as condições gastrointestinais dos peixes a uma temperatura de $26^{\circ} \mathrm{C}$ (temperatura média ideal de acondicionamento das tilápias). $\mathrm{O}$ perfil de liberação das bactérias nos diferentes valores de $\mathrm{pH}$ e a variação de tamanho das micropartículas são mostrados na Tabela 4.

Tabela 4. Perfil de liberação bacteriana de micropartículas contendo 14,3 $\mathrm{g}$ de bactéria/L de gel de alginato em soluções aquosas apresentando diferentes valores de $\mathrm{pH}$ e variação do diâmetro após exposição a estas condições

\begin{tabular}{ccc}
\hline $\begin{array}{c}\text { pH da solução } \\
\text { de incubação }\end{array}$ & $\begin{array}{c}\text { Fração de bactérias } \\
\text { liberadas após } 12 \mathrm{~h}(\%)\end{array}$ & $\begin{array}{c}\text { Diâmetro médio } \\
\text { após } 12 \mathrm{~h}(\mu \mathrm{m})\end{array}$ \\
\hline 2,0 & 2,9 & $28 \pm 2$ \\
4,5 & 2,9 & $27 \pm 1$ \\
7,4 & 2,8 & $31 \pm 3$ \\
9,0 & 2,9 & $30 \pm 2$ \\
\hline
\end{tabular}

* Diâmetro médio inicial das micropartículas para todos os casos: $32 \pm 1$

Em todos os casos, a variação de diâmetros foi inferior a 15\%, e a quantidade de bactérias liberadas foi menor que $3 \%$, o que indica que as micropartículas possuem a capacidade de manter-se como um gel íntegro, protegendo efetivamente o agente encapsulado, ${ }^{14}$ sendo, portanto, ideais neste sentido para a vacinação oral. Estes resultados são condizentes com o trabalho de outros autores. ${ }^{17,23,34}$ Como a liberação do agente encapsulado pode ocorrer por mecanismos difusivo e pela degradação da rede polimérica da matriz de alginato e uma vez que a quantidade de agente antigênico liberado após a incubação foi muito pequena, pode-se supor que a liberação do agente ocorreu 
preferencialmente pelo mecanismo difusivo, já que as partículas mantiveram-se praticamente íntegras quando submetidas às condições gastrointestinais simuladas. Observou-se que as amostras não apresentaram mudança morfológica significativa ao longo da exposição às diferentes condições de $\mathrm{pH}$.

Sendo assim, o comportamento das micropartículas frente às variações de $\mathrm{pH}$ se mostrou bastante satisfatório, uma vez que o agente antigênico praticamente não foi liberado nas condições gastrointestinais simuladas da tilápia do Nilo. Assim, hipoteticamente, os possíveis processos de desnaturação e degradação das proteínas bacterianas seriam prevenidos, dando maior oportunidade às micropartículas de transporem a parede intestinal e, uma vez na corrente sanguínea, liberarem lenta e eficazmente o material incorporado. Ensaios in vivo estão em andamento para a análise da eficiência do uso deste sistema na imunização oral de tilápias do Nilo.

\section{CONCLUSÕES}

No presente estudo pode-se observar que a metodologia apresentada mostrou-se capaz

de produzir um veículo de administração oral de vacina para peixes com diâmetro médio inferior a $35 \mu \mathrm{m}$. As micropartículas preparadas à temperatura de $25^{\circ} \mathrm{C}$ pelo uso de impelidor naval foram capazes de encapsular praticamente $100 \%$ das células inativadas de Flavobacterium columnare, e resistiram às condições adversas de alteração de $\mathrm{pH}$ em condições gastrointestinais simuladas, de modo que em todas as situações, a quantidade de bactérias liberadas foi inferior a $3 \%$.

\section{MATERIAL SUPLEMENTAR}

As Figuras 1S, 2S, 3S e 4S estão disponíveis, como material suplementar, em http://quimicanova.sbq.org.br, na forma de arquivo PDF, com acesso gratuito.

\section{AGRADECIMENTOS}

Este trabalho foi realizado com o apoio do Conselho Nacional de Desenvolvimento Científico e Tecnológico (CNPq) e da Fundação de Amparo à Pesquisa do Estado de Minas Gerais (FAPEMIG), Brasil. Os autores agradecem ao Prof. Dr. E. Sabadini e ao doutorando M. V. C. Cardoso, do Departamento de Físico-Química do Instituto de Química da Universidade Estadual de Campinas pelo auxílio na realização das análises de viscosidade.

\section{REFERÊNCIAS}

1. Austin, B.; Austin, D. A.; Bacterial Fish Pathogens: disease in farmed and wild fish, Ellis Horwood Ltd.: Chichester, 1987.

2. Tripathi, N. K.; Latimer, K. S.; Gregory, C. R.; J. Vet. Diagn. Invest. 2005, 17, 45 .
3. Suomalainen, L. R.; Dissertação, Jyväskylä University, Finlândia, 2005.

4. Schmidt, A. S.; Bruun, M. S.; Dalgaard, I.; Pedersen, K.; Larsen, J. L.; Appl. Environ. Microbiol. 2000, 66, 4908.

5. Thorarinsson, R.; Powell, D. B.; Aquaculture 2006, 256, 42.

6. Xing, L.; Dawei, C.; Liping, X.; Rongquing, Z.; J. Controlled Release 2003, 93, 293.

7. van der Lubben, I. M.; Verhoef, J. C.; van Aelst, A. C.; Borchard, G.; Junginger, H. E.; Biomaterials 2001, 22, 687.

8. Wikingsson, L. D.; Sjöholm, I.; Vaccine 2002, 20, 3355.

9. Tian, J., Yu, J.; Sun, X.; Vet. Immunol. Immunopathol. 2008, 126, 220.

10. Joosten, P. H. M.; Tiemersma, E.; Threels, A.; Caumartin-Dhieux, C.; Rombout, J. H. W. M.; Fish Shellfish Immunol. 1997, 7, 471.

11. Ellis, A. E.; J. Appl. Ichthyol. 1998, 14, 149.

12. Singh, M.; O'Hagan, D.; Adv. Drug Delivery Rev. 1998, 34, 285.

13. Romalde, J. L.; Luzardo-Alvaréz, A.; Ravelo, C.; Toranzo, A. E.; Blanco-Mendez, J.; Aquaculture 2004, 236, 119.

14. George, M.; Abraham, T. E.; J. Controlled Release 2006, 14, 1.

15. Poncelet, D.; Smert, B. P. D.; Beaulieu, C.; Huguet, A.; Fournier, A.; Neufeld, R. J.; Appl. Microbiol. Biotechnol. 1995, 43, 644.

16. Reis, C. P.; Neufeld, R. J.; Vilela, S.; Ribeiro, A. J.; Veiga, F.; J. Microencapsulation 2006, 23, 245.

17. Lemoine, D.; Wauters, F.; Bouchend'homme, S.; Pre'at, V.; Int. J. Pharm. 1998, 176, 9.

18. Poncelet, D.; Babak, V.; Dulieu, C.; Picot, A.; Colloids Surf., A 1999, $155,171$.

19. Mofidi, N.; Aghai-Moghadam, M.; Sarbolouki. M. N.; Process Biochem. 2000, 35, 885 .

20. Hildebrand, G. E.; Tack, J. W.; Int. J. Pharm. 2000, 196, 173.

21. Ribeiro, A. J.; Neufeld, R. J.; Arrnaud, P.; Chameil, J. C.; Int. J. Pharm. 1999, 187, 115.

22. Wan, L. S. C.; Heng, P. W. S.; Chan, L. W.; Int. J. Pharm. 1994, 103, 267.

23. Rodrigues, A. P.; Hirsch, D.; Figueiredo, H. C. P.; Logato, P. V. R.; Moraes, A. M.; Process Biochem. 2006, 41, 638.

24. Figueiredo, H. C. P.; Klesius, P. H.; Arias, C. R.; Evans, J.; Shoemaker, C. A.; Pereira, D. J. Jr.; Peixoto, M. T.; J. Fish Dis. 2005, 28, 199.

25. Almutairi, S. H.; Tese de Doutorado, Texas A\&M University, EUA, 2008.

26. Pal, R.; AIChE J. 1996, 42, 3181.

27. Opawale, F. O.; Burguess, D. J.; J. Colloid Interface Sci. 1998, 197, 142.

28. Schubert, H.; Int. J. Miner. Process. 2005, 75, 11.

29. Ribeiro, A. J.; Silva, C.; Ferreira, D.; Veiga, F.; Int. J. Pharm. Sci. 2005, 25,31 .

30. Silva, C. M.; Ribeiro, A. J.; Figueiredo, M.; Ferreira, D.; Veiga, F.; AAPS J. 2006, 4, E903.

31. Kichatov, B. V.; Korshunov, A. M.; Boiko, I. V.; Assorova, P. V.; Theor. Found. Chem. Eng. 2003, 37, 19

32. Joaquim Junior, C. F.; Cekinski, E.; Nunhez, J. R.; Urenha, L. C.; Agitação e mistura na indústria, LTC: Rio de Janeiro, 2007.

33. Thomas-Jinu, S.; Goodwin, A. E.; J. Fish Dis. 2004, 27, 29.

34. Sugawara, S.; Imai, T.; Otagiri, M.; Pharm. Res. 1994, 11, 272. 


\section{PRODUÇÃO DE MICROPARTÍCULAS DE ALGINATO CONTENDO Flavobacterium columnare INATIVADA PELO MÉTODO DE EMULSÃO PARA VACINAÇÃO DE PEIXES POR VIA ORAL}

Priscila Soares Costa Sacchetin e Ângela Maria Moraes*

Departamento de Processos Biotecnológicos, Faculdade de Engenharia Química, Universidade Estadual de Campinas, Cidade Universitária “Zeferino Vaz”, CP 6066, 13083-970 Campinas - SP, Brasil

Carlos Augusto Gomes Leal e Henrique César Pereira Figueiredo

Departamento de Medicina Veterinária, Universidade Federal de Lavras, Campus Universitário, CP 37, 37200-000 Lavras - MG, Brasil

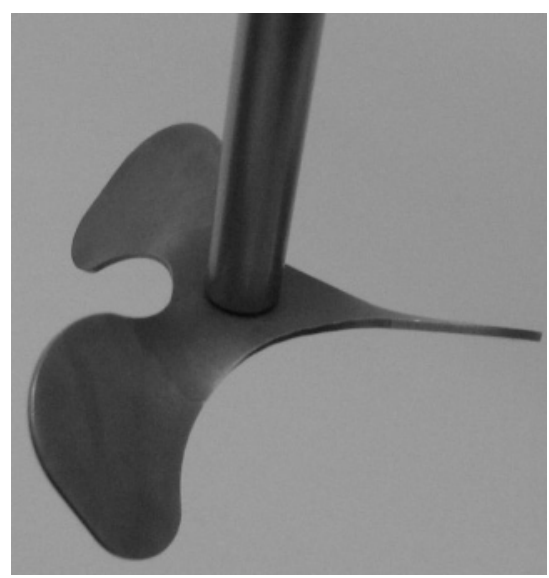

Figura 1S. Impelidor naval

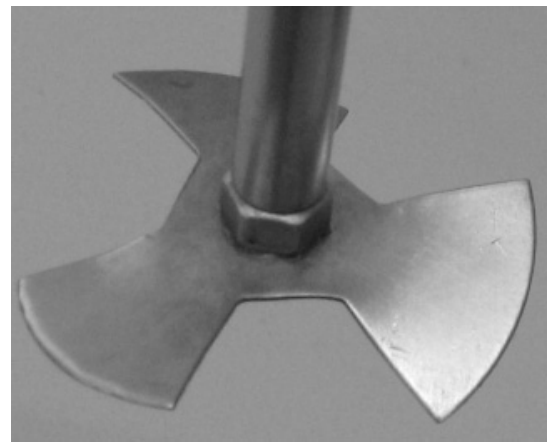

Figura 2S. Impelidor de pás inclinadas

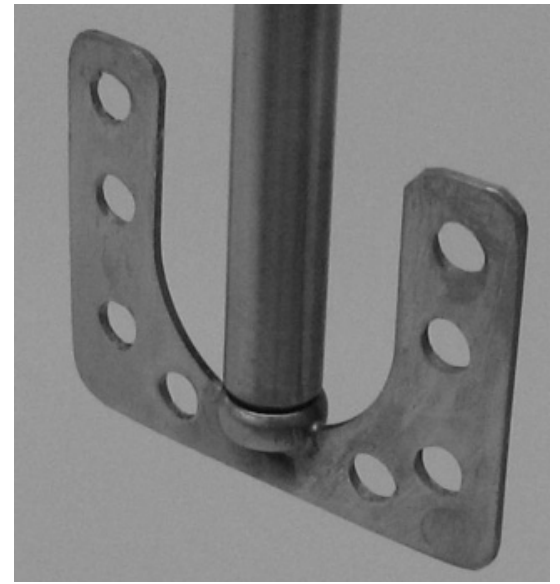

Figura 3S. Impelidor âncora perfurada

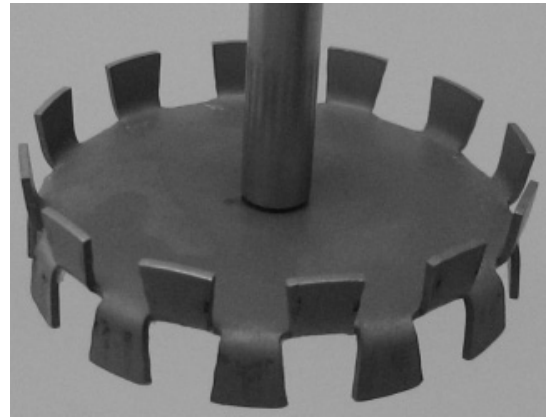

Figura 4S. Impelidor centrífugo 